\title{
Is there a golden age in publication activity?-an analysis of age-related scholarly performance across all scientific disciplines
}

\author{
Balázs Győrffy ${ }^{1,2}$ (D) · Gyöngyi Csuka ${ }^{3}$ · Péter Herman ${ }^{1,2}$ · Ádám Török ${ }^{4,5}$
}

Received: 27 August 2019 / Published online: 15 May 2020

(c) The Author(s) 2020

\begin{abstract}
We examined whether the publication characteristics of various scientific disciplines exhibit age-related trends. Our analysis was based on two large data sets comprising all major scientific disciplines. Citation data for European Research Council grant holders (ERC, $n=756$ ) were obtained from Google Scholar. Publication data for Hungarian researchers (HUN, $n=2469$ ) were obtained from the Hungarian Scientific Work Archive. The evaluated performance parameters include the number of citations received and the number of high quality first/last author papers published in the last five years. We designated the time between maximum growth and the achieved maximal annual value of total citations as the Golden Age of a researcher. Regarding citation growth, the mean age at the highest growth was 41.75 and 41.53 years for ERC grantees and Hungarian researchers, respectively. Each discipline had different values, with mathematics (38.5 years, ERC) and biology (34.7 years, HUN) having the youngest mean age of highest citation growth and agriculture (45.2 years, ERC) and language sciences (49.9 years, HUN) having the oldest mean age. The maximal growth of publications occurred at 44.5 years, with physics starting first (40.5 years, HUN) and language sciences as last (51.4 years, HUN). Most academic careers require decades to reach their peak and the length of the period of maximum performance varies across disciplines. The most creative time period is rising and is currently in the second half of the forties. Identifying the Golden Age in diverse research careers may be of substantial help in the distribution of grants and tenure positions.
\end{abstract}

Keywords Scientific performance $\cdot$ Citation $\cdot$ ERC $\cdot$ HSWA $\cdot$ Scientific discipline

The authors would like to thank Sándor Habi (PhD student, University of Pannonia) for his help compiling the ERC database.

Balázs Győrffy

gyorffy.balazs@med.semmelweis-univ.hu

Extended author information available on the last page of the article 


\section{Introduction}

Olympic athletes and artists have highly productive years typical to their disciplines, with significant exceptions in certain fields of arts. In music, for example, Liszt, Haydn, Verdi and Strauss produced their last masterpieces over the age of 70 , while the similarly longlived Rossini and Sibelius ceased composing in their forties. There are a number of scientific fields, including physics and biology, in which great contributions were made by scholars under 30 years of age. Évariste Galois was 21 when he outlined group theory in mathematics the night before his mortal duel, and James Watson was 25 when he discovered the structure of DNA. Albert Einstein produced the theory of special relativity at the age of 26, and Isaac Newton started his groundbreaking work on color theory and the theory of gravitation when only 24 (Zuckerman and Merton 1972, p. 308; Cole 1979, p. 958; Devlin 1998).

Naturally, the question arises whether age is a crucial factor in the development of scholarly output? Research careers may be in 1. improving, 2. peaking, and 3. declining track. When considering this issue on a large scale, a couple of research questions arise: \#1 could a Golden Age of publication activity be demarcated in creative scholarly careers; \#2 are there any discipline-specific patterns of the Golden Age in various fields of science; and \#3 could Golden Age in any discipline be interpreted as a predictive factor in assessing the output expected from research proposals?

Based on Lehman (1953), Fox (1983) produced the first results in Golden Age-related research. For Lehman, individual scholarly performance typically peaks at approximately the end of the scholar's thirties or in the early forties. Further research by Lehman (1958, 1960) showed that this peak could be reached earlier in abstract fields of science, including mathematics and theoretical physics or biology. In empirical scientific disciplines, such as geology or biology, the most active years arrive later (Fox 1983). Lehman's (1958) conclusion for chemistry was somewhat different. His career analysis of 2500 prominent chemists placed their most productive years between 30 and 34 years of age.

Other early research on the development of individual scholarly activity over time identified two peaks (Pelz and Andrews 1966). The first, most productive time period occurs at the end of the thirties, the second approximately 15 years later (Fox 1983). Bayer and Dutton (1977) also identified two career peaks for higher education staff in physics, biochemistry, earth sciences, chemical engineering, experimental psychology, economics and sociology. The first peak was observed after 10 years had been spent on research and the second one when approaching retirement. A marked exception was biochemistry: one career peak at approximately year 20 of active professional life. A further, less obvious outlier was chemical engineering, which displayed wave-like characteristics with peaks around years 10 and 30 (Bayer and Dutton 1977).

In a comparative analysis of six countries, Knorr et al. (1979) produced results that seem to contradict the hypothesis of a Golden Age in research careers. They found that scholarly performance depends much more on task environment than age. Higher positions in the hierarchy are instrumental in improving publication output owing to better access to funding.

Gingras et al. (2008) used the database of the National Institutes of Health to highlight a certain time shift in what is referred to here as the Golden Age. The average age of PhDs obtaining their first Principal Investigator grant was 34.3 years in the 1970s in the U.S. and 41.7 in 2004. This significant change was duplicated by an increase in the average age of appointment of tenured professors in American medical schools: 34 to 36 years in the 1980s to 
37.5 to 40 in 2004. A similar increase occurred in Canada with the increase in the average age of university professors from 42-49 years between 1976 and 1998.

An increase in the average age of one type or another of the first major milestone of a scholarly career does not seem closely related to the development of individual performance. Gingras et al. (2008) analyzed a sample of more than 6000 university professors and researchers from Quebec for the time period 2000 to 2007. They identified two turning points in the surveyed scholarly careers. The first occurred at approximately age 40, with a marked slowdown of the hitherto fast improvement of scholarly productivity. The second turning point arrived approximately 10 years later. Active professors above 50 years of age could still boast high productivity, but their average scientific impact was markedly down.

More seasoned professors tend to be first authors less frequently, and their ranking positions among co-authors are likely to deteriorate. The authors consider this as evidence of the Matthew effect: first authors tend to be younger, while their elder colleagues are heads of research teams consisting of less experienced colleagues (Gingras et al. 2008). Costas et al. (2010) came to similar conclusions after analyzing a Web of Science-based sample of publication and citation data on researchers in three fields between 1994 and 2004. Ageing typically entails the decrease of time devoted to research, at least in a sample from Japan (Kawaguchi et al. 2016). A possible explanation for this phenomenon could be an increase in administrative tasks for more experienced researchers (Kawaguchi et al. 2016).

The one-peak model seems to apply for the four major universities of Norway (University of Oslo, University of Bergen, Norwegian University of Science and Technology in Trondheim, University of Troms $\varnothing$ ), which produce $70 \%$ of the publications of the country's higher education system. According to Rørstad and Aksnes (2015), the sole peak occurs in the age window of 40-50 years in the humanities, social sciences, natural sciences, engineering and technology, and medicine. Exceptions were few, mainly in the social sciences, where no decrease followed the peak.

Many studies have been limited to single countries, institutions or fields of science (e.g., Wallner et al. 2003; Bonaccorsi and Daraio 2003; Costas et al. (2010); Lima et al. 2015; Verleysen and Ossenblok 2017; Way et al. 2017) and therefore yield only partial results. Factors of individual scientific output other than age include gender, tenure or professional status, and their impacts have been widely studied (Bonaccorsi and Daraio 2003; Costas et al. 2010; (Abramo et al. 2018). Institutional factors have also been analyzed (Akbaritabar et al. 2018), as have the impacts of cooperation (Lee and Bozeman 2005; Sugimoto et al. 2016) or the role of productivity, impact, randomness and luck during a career (Sinatra et al. 2016; Liu et al. 2018).

The aim of our research is to identify the relationship between age and scholarly performance for all disciplines using multiple independent data sets wherever possible.

A notable hindrance to realizing this research goal is the difficulty of precisely delineating disciplines or fields of science. There is no universally accepted system of classification of scientific disciplines. One widely used general scheme is based on the distinction between the natural sciences, life sciences and the social sciences/humanities. This scheme is, however, insufficiently detailed to reflect significant differences between, for example, mathematics and chemistry within the natural sciences, applied genetics and pediatrics within life sciences, or archeology and economics within the social sciences/humanities. 


\section{Methods}

\section{ERC grant holders}

ERC grant holders were identified using the homepage of the European Research Council (ERC, http://erc.europa.eu). Only grantees with an advanced grant were considered, and for each researcher, the scientific discipline was noted. A Google search was performed for each grantee to establish the birth year, which is crucial to estimating career stage. Only publicly available data were used, and researchers were anonymized for the statistical computations. For ERC grants, citation data for each grant holder were downloaded from Google Scholar (https://scholar.google.com/). We utilized Google Scholar instead of the Web of Science or Scopus because it offers better coverage of certain scientific disciplines, including the humanities (including literature and art), the social sciences, engineering and computer science, economics and management (Martín-Martín et al. 2018; Gusenbauer 2019). Notably, certain ERC fellows among the ERC researchers received more than 10,000 citations per year. One reason for this high number could be the higher citation rate for original books than periodicals. In addition, first- or second-authored publications tend to receive more citations (Hartley 2019).

We only used publicly available data. Unpublished personal data were not collected from any of the subjects. In the case of identical names, the scientific discipline was used to discriminate the researchers. We selected birth year over year of $\mathrm{PhD}$ because the latter was more complicated to obtain. In addition, numerous fellows start their scientific research when still in graduate school, making the date of $\mathrm{PhD}$ unsuitable when assessing their progress.

\section{Hungarian researchers}

More detailed publication and citation characteristics were available in the Hungarian Scientific Work Archive (HSWA https://www.mtmt.hu/) for Hungarian researchers. HSWA is a national bibliographic scientific database which is law-regulated and enforces the collection of all national and international publications and citations for Hungarian researchers. HSWA was initially established in 2008 and is currently under the supervision of the Hungarian Academy of Sciences. Validated and updated data from the HSWA is necessary to achieve a full professor position at any of the Hungarian universities or to obtain the Doctor of the Academy title from the Hungarian Academy of Sciences.

Data, including published papers, author lists, and independent citations received, were retrieved on the 1st of January, 2019. For Hungarian researchers, only data on Doctors of the Academy (a type of tenured professorship granted by the Hungarian Academy of Sciences), members of the Academy, and Momentum grant holders (Gyorffy et al. 2018) were downloaded. The reason for this restriction was that scientists in the described cohorts are required to regularly maintain and update their HSWA profiles, while other researchers only perform this updating on a voluntary basis. The Momentum grant scheme was launched in 2009 by the Hungarian Academy of Sciences and it provides research budget of up to EUR 1 million for five years to young scientists (those below the age of 45). The goal of the Momentum grant program is to offer internationally competitive opportunities for the top Hungarian researchers. Momentum grant winners can come from any scientific 
discipline but have to possess a PhD degree and must provide evidence of a high-ranking scientific track record.

Birth year was downloaded for each researcher from the database of the Hungarian Doctoral Council (https//www.doktori.hu). Only publicly available data were used in the project.

\section{Scientific disciplines}

To link researchers to scientific disciplines, we adopted the system of classification used by the Hungarian Academy of Sciences. This scheme is highly practice-oriented and reflects a visible effort to create integrated sectors of science in which size and quality are comparable. The three sectors include the natural sciences (mathematics, technical sciences, chemistry, earth sciences and physics), life sciences (agricultural sciences, medicine, and biology) and the social sciences/humanities (literature and linguistic sciences, history, philosophy, and economic and legal sciences). Each of the three main sectors contains important overlapping fields not listed above. For example, IT science is shared between mathematics and technical sciences, psychology belongs to history and philosophy, and social geography is included in earth sciences.

HSWA assigns researchers to scientific disciplines based on the organizational structure of scientific disciplines of the Hungarian Academy of Sciences (HAS). We matched these HAS categories to the ERC classes (Table 1).

\section{Journal ranking}

The assignment of journals to the top $10 \%$ of publications in a given scientific discipline was performed using data from the SCImago Journal \& Country Rank portal (http://www. scimagojr.com). In this database, all journals in a given category are ranked. Journals in the first decile were designated as "D1" journals of the respective category. Because we were interested in top scientific performance, only publications in D1 journals were included when evaluating first/last author publications. The data set was retrieved in January 2019. In the investigated sample, 10,553 of the total of 22,883 journals $(46.1 \%)$ were ranked in SCImago. First/last author designation was only available in the HSWA database.

\section{Statistical analyses}

Citations received were averaged for two consecutive years. In this, the citation sum received during the given year for each previous publication of the author was computed. Then, similarly to the computation of the impact factors, the mean of two consecutive years were derived. This number was computed for each age year of each researcher.

For the five-years sum of D1 articles we looked up all articles published by the given author, then for each publication a SCimago journal rank was assigned, and the list of the publications was filtered to include only those with a D1 rank. Then, the list was filtered to include only first- and last-author publications, and all such articles in the preceding five years were summed to generate a value for a given year.

For both the two-year citations mean and the number of D1 articles in five years, the maximum value was determined for each researcher. 
Table 1 Connection between the two different scientific discipline classifications used in our study: the European Research Council (left) and the Hungarian Academy of Sciences (right)

ERC panel HAS panel

Life Sciences

LS1 Molecular Biology, Biochemistry, Structural Biology and Molecular Bio- $\quad$ Biology physics

LS2 Genetics,'Omics', Bioinformatics and Systems Biology Biology

LS3 Cellular and Developmental Biology Biology

LS4 Physiology, Pathophysiology and Endocrinology Medicine

LS5 Neuroscience and Neural Disorders Medicine

LS6 Immunity and Infection Medicine

LS7 Applied Medical Technologies, Diagnostics, Therapies and Public Health Medicine

LS8 Ecology, Evolution and Environmental Biology Biology

LS9 Applied Life Sciences, Biotechnology, and Molecular and Biosystems Agriculture Engineering

Physical sciences and engineering

PE1 Mathematics

Mathematics

PE2 Fundamental Constituents of Matter Physics

PE3 Condensed Matter Physics Physics

PE4 Physical and Analytical Chemical Sciences Chemistry

PE5 Synthetic Chemistry and Materials Chemistry

PE6 Computer Science and Informatics Mathematics

PE7 Systems and Communication Engineering Engineering

PE8 Products and Processes Engineering Engineering

PE9 Universe Sciences Physics

PE10 Earth System Science Earth sciences

Social sciences and humanities

SH1 Individuals, Markets and Organizations

Economics and law

SH2 Institutions, Values, Environment and Space

Language sciences

SH3 The Social World, Diversity, Population

Philosophy and history

SH4 The Human Mind and Its Complexity

Philosophy and history

SH5 Cultures and Cultural Production

Language sciences

SH6 Archaeology and history

Philosophy and history

The change in the year/year value of citation and D1 publications was computed for each year, and the highest growth value was also noted for each scientist.

In this analysis, results with a baseline value of 0 were excluded (because they would indicate infinite relative growth). When determining the maximum value, researchers with a maximum value in 2017 were also excluded because they were still in a rising trend. The year 2018 was not considered because of potentially incomplete publication data for that year.

Using the above data we designated the time between maximum growth and the achieved maximal annual value of total citations as the Golden Age of a researcher. Maximal annual value is, of course, not an equally robust measure for output in all disciplines, but we feel it has some shortcomings only in such fields of descriptive social sciences where output appears partly in books which count as one publication each in spite of containing material equal to 10,20 or even 30 articles. We suppose, however, that this potential 
distortion does not affect our field-specific findings since it may only weaken across-fields comparisons to a certain extent.

Database handling and analysis was executed in the $\mathrm{R}$ statistical environment using "httr" and "rvest" libraries for downloading and the "stringr" and "dplyr" libraries for text processing and data handling, respectively. Continuous variables between the different scientific disciplines were compared by the Kruskal-Wallis test using WinStat for Excel (R. Fitch Software, Germany). The results are presented as the mean $\pm 95 \%$ confidence intervals. The threshold for statistical significance was set at $p<0.05$.

\section{Results}

The entire set of ERC researchers included 2409 grant winners (some have received the grant multiple times; see below). We excluded those without an available birthdate $(n=1137,47.2 \%)$, those without a Google Scholar account and Hungarian researchers (in total, $n=1653,68.6 \%$ ). Hungarian researchers were excluded because for them a more detailed database was available in the HSWA database, and thus, they were analyzed together with the other researchers based Hungary. This approach ensured complete independence of the two investigated cohorts. Citation data for 756 ERC advanced grant holders were collected. Researchers of the Hungarian Academy of Sciences included $n=2380$ fellows.

We feel our ERC dataset is apt for drawing quite robust conclusions in spite of its seemingly limited size. As mentioned above, only grantees with advanced grants were included since these ERC sponsored researchers can be supposed to have research careers long enough to be evaluated for their Golden Age. On the other hand, it is not exceptional in social sciences to work with samples with limited sizes in order to benefit from greater homogeneity. It should suffice to mention Nobel Laureate Kahneman from experimental economics, whose seminal work (Kahneman 2011) contains a number of experiments with sample sizes below 100 .

The distribution of the different scientific disciplines and descriptive characteristics for all researchers, including a birth-year distribution and the gender balance (only for Hungarian researchers), are provided in Fig. 1.

\section{Citation trend-ERC}

The maximal citation using data from two consecutive years was reached at a mean age of $57.2 \pm 0.87$ years. The earliest toppers were language scientists $(54.2 \pm 3.74$ years $)$ and the latest those in agricultural sciences $(64.2 \pm 6.23$ years). The mean of the numerical values of yearly citation ranged between $1303 \pm 426$ (language sciences) and $4039 \pm 1063$ (medicine). The average across the entire sample was $2474 \pm 233$ citations. These results include both dependent and independent citations as well as citations from non-peer-reviewed sources, such as patents, because Google Scholar does not distinguish between these citation types.

The mean age of the maximal citation growth was $41.8 \pm 0.56$ years for all ERC advanced grant holders. The youngest were the mathematicians ( $38.6 \pm 1.23$ years), and the oldest were those in agricultural research $(45.2 \pm 4.65$ years). Regarding maximal growth, those with the most dynamic expansion were active in medicine (yearly mean growth 
(A)

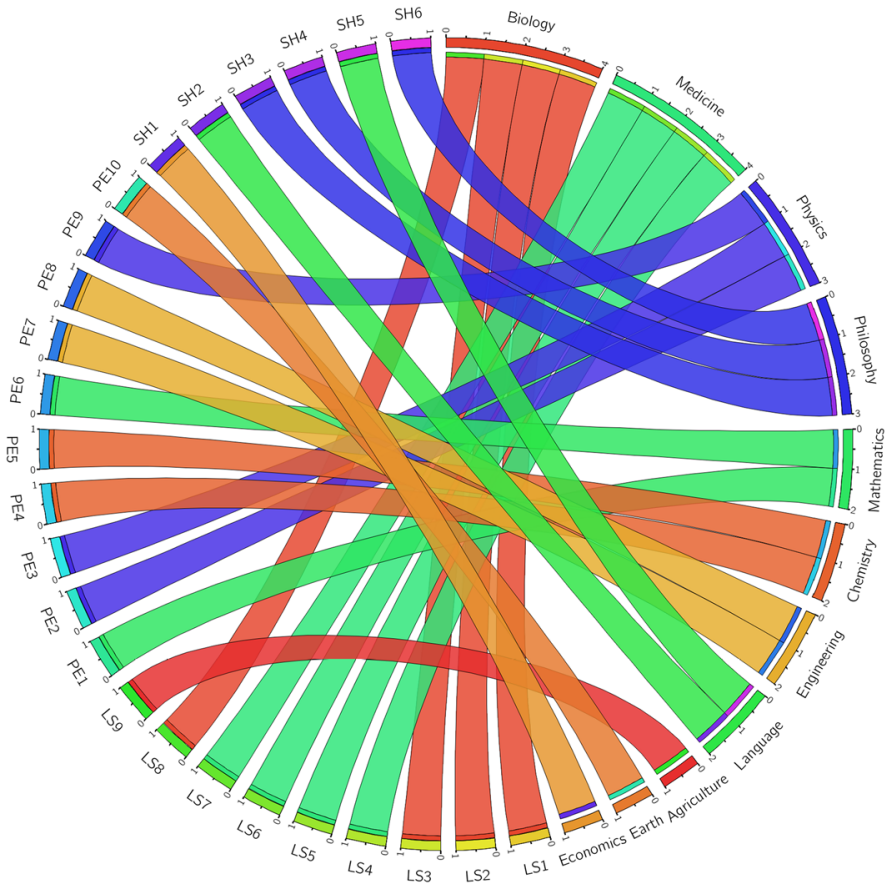

(B)

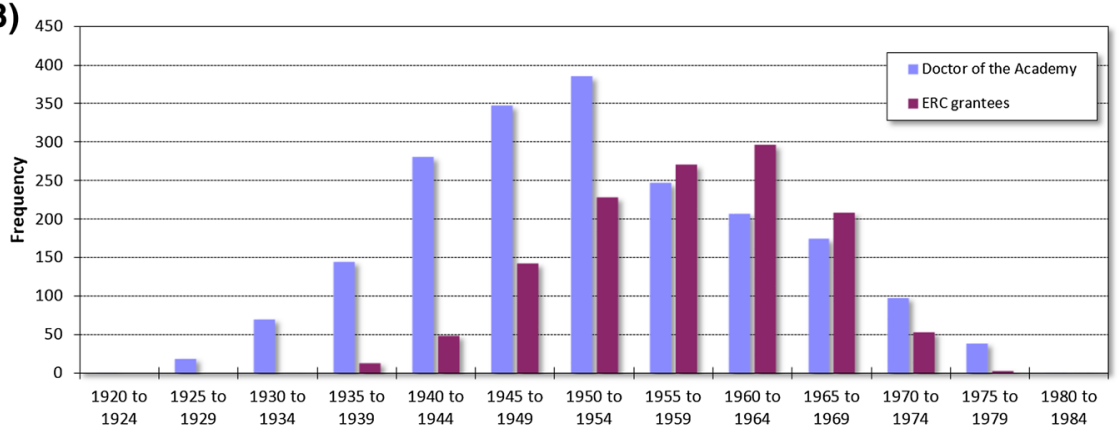

(C)

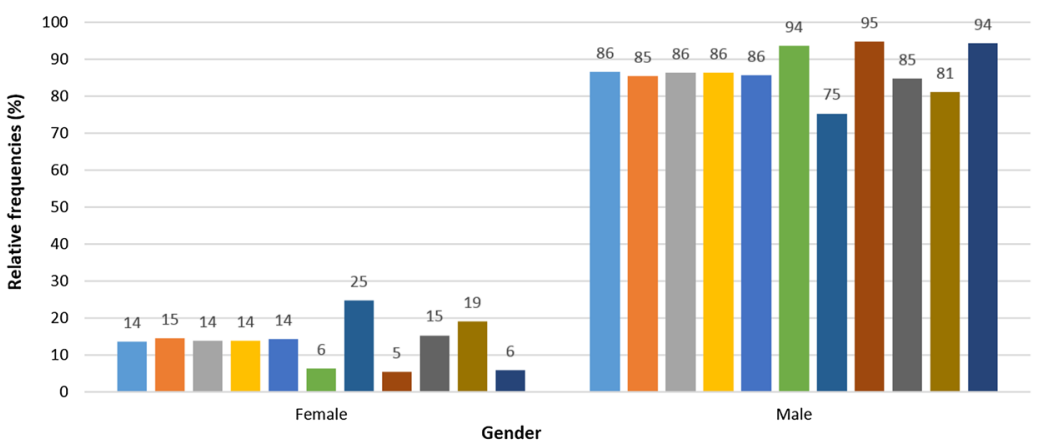

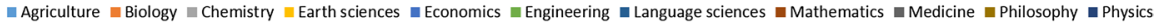

Fig. 1 Descriptive and epidemiological characteristics of the researchers analyzed in the study Linking disciplines assigned to the different ERC panels and disciplines of the HAS (a). Age distribution of all ERC and all HAS researchers (b) Distribution of gender among all HAS scientists (c) 
Table 2 Number of citations received in the last two years for ERC grantees (A) and HAS researchers (B)

\begin{tabular}{|c|c|c|c|c|c|c|c|c|c|}
\hline & \multirow[b]{3}{*}{$\mathrm{N}$} & \multicolumn{4}{|c|}{ Maximal citation growth } & \multicolumn{4}{|c|}{ Maximal citation } \\
\hline & & \multicolumn{2}{|l|}{ Age } & \multicolumn{2}{|c|}{ Percentage } & \multicolumn{2}{|l|}{ Age } & \multicolumn{2}{|c|}{ 2-year citation } \\
\hline & & Mean & $\mathrm{CI}( \pm)$ & Mean & $\mathrm{CI}( \pm)$ & Mean & $\mathrm{CI}( \pm)$ & Mean & $\mathrm{CI}( \pm)$ \\
\hline \multicolumn{10}{|l|}{ A } \\
\hline Agriculture & 16 & 45.19 & 4.65 & $142 \%$ & $6 \%$ & 64.17 & 6.23 & 2685 & 1594 \\
\hline Biology & 108 & 39.36 & 1.49 & $176 \%$ & $16 \%$ & 55.39 & 2.01 & 2967 & 738 \\
\hline Chemistry & 68 & 42.62 & 1.97 & $174 \%$ & $26 \%$ & 57.94 & 2.94 & 3700 & 1156 \\
\hline Earth sci. & 32 & 43.09 & 2.5 & $152 \%$ & $6 \%$ & 60 & 4.12 & 2066 & 455 \\
\hline Economics & 40 & 41.48 & 2.16 & $155 \%$ & $7 \%$ & 57.94 & 3.36 & 1991 & 778 \\
\hline Engineering & 61 & 42.15 & 1.63 & $152 \%$ & $5 \%$ & 58.83 & 3.25 & 2224 & 470 \\
\hline Language sci. & 42 & 43.64 & 1.87 & $158 \%$ & $6 \%$ & 54.23 & 3.74 & 1303 & 426 \\
\hline Mathematics & 111 & 38.56 & 1.23 & $156 \%$ & $5 \%$ & 54.24 & 1.9 & 1583 & 421 \\
\hline Medicine & 87 & 43.14 & 1.81 & $211 \%$ & $33 \%$ & 58.02 & 2.18 & 4039 & 1063 \\
\hline Philosophy & 72 & 43.72 & 1.97 & $179 \%$ & $28 \%$ & 61.59 & 3.56 & 1376 & 271 \\
\hline Entire sample & 756 & 41.75 & 0.56 & $169 \%$ & $6 \%$ & 57.2 & 0.87 & 2474 & 233 \\
\hline \multicolumn{10}{|l|}{ B } \\
\hline Agriculture & 181 & 44.68 & 1.82 & $460.6 \%$ & $53.4 \%$ & 59.99 & 1.52 & 67.9 & 10.8 \\
\hline Biology & 288 & 34.77 & 1.04 & $457.6 \%$ & $32.9 \%$ & 55.52 & 1.36 & 214.7 & 28.0 \\
\hline Chemistry & 259 & 36.51 & 1.10 & $425.0 \%$ & $25.9 \%$ & 60.18 & 1.33 & 154.5 & 17.4 \\
\hline Earth sci. & 109 & 44.06 & 2.38 & $406.8 \%$ & $42.0 \%$ & 61.82 & 1.97 & 56.8 & 13.1 \\
\hline Economics & 202 & 49.50 & 1.86 & $396.6 \%$ & $28.1 \%$ & 58.35 & 1.56 & 24.8 & 5.8 \\
\hline Engineering & 209 & 47.64 & 1.86 & $395.4 \%$ & $28.0 \%$ & 59.16 & 1.65 & 43.4 & 8.5 \\
\hline Language sci. & 163 & 49.95 & 2.10 & $405.9 \%$ & $42.7 \%$ & 56.14 & 1.78 & 12.0 & 2.6 \\
\hline Mathematics & 166 & 37.70 & 1.52 & $405.9 \%$ & $29.9 \%$ & 57.54 & 1.68 & 68.0 & 15.5 \\
\hline Medicine & 405 & 39.57 & 1.08 & $434.2 \%$ & $25.6 \%$ & 58.98 & 1.05 & 202.8 & 26.6 \\
\hline Philosophy & 192 & 46.87 & 1.78 & $393.4 \%$ & $39.4 \%$ & 55.44 & 1.43 & 33.3 & 11.1 \\
\hline Physics & 206 & 34.45 & 1.32 & $461.5 \%$ & $47.7 \%$ & 54.17 & 1.73 & 218.0 & 59.0 \\
\hline Entire sample & 2380 & 41.53 & 0.51 & $425.4 \%$ & $10.7 \%$ & 57.86 & 0.46 & 115.3 & 8.4 \\
\hline
\end{tabular}

CI $95 \%$ confidence interval

$211 \pm 33 \%$ ). The citation values and growth characteristics are summarized in Table $2 \mathrm{~A}$ and Fig. 2a.

There were 92 ERC grant holders who received the grant twice. To assess the overall excellence of these researchers, the age-related citation number was computed and compared to that of one-time ERC grantees. Overall, between ages 35 and 65, those receiving the grant multiple times were between the 52nd and 60th percentile of all ERC grantees.

\section{Citation trend-HSWA}

The highest value for 2-year cumulative citation was reached at a mean age of $57.8 \pm 0.46$ years for all researchers. Physicists constituted the youngest cohort $(54.2 \pm 1.73$ years $)$ and geologists the oldest $(61.8 \pm 2.0$ years $)$. Regarding the numerical values, the highest mean citation was $218 \pm 59$ (physicists), and the lowest value was 
(A)

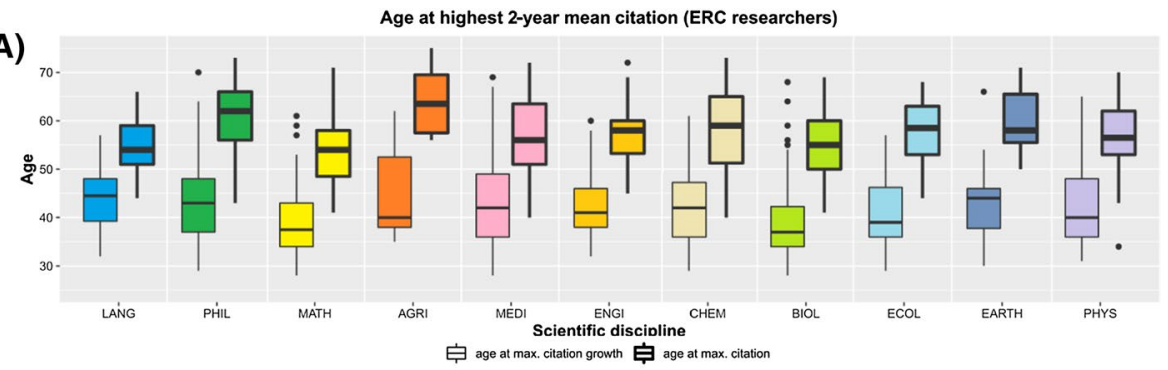

(B)

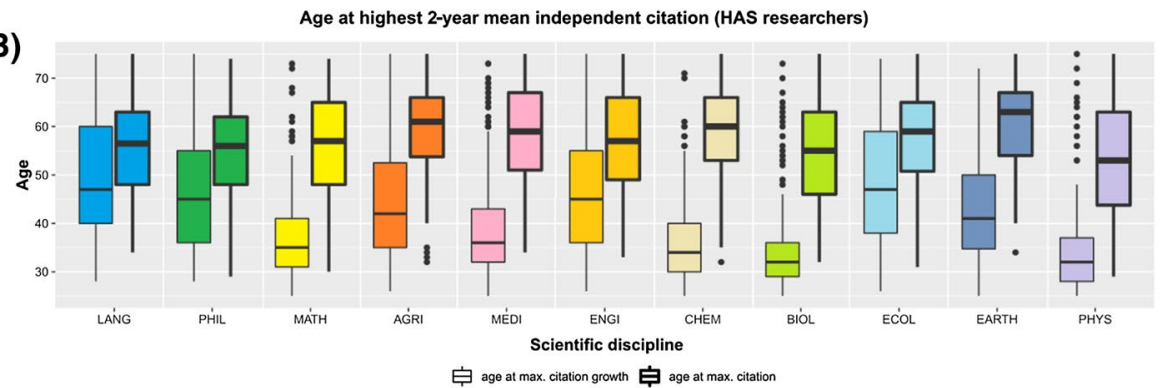

(C)

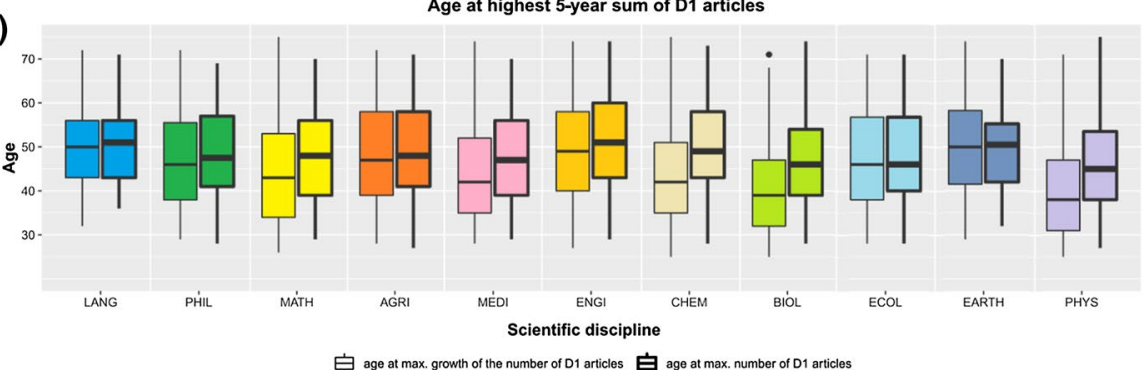

Fig. 2 The highest impact in terms of received citations of a researcher is reached typically between 55 and 65 years of age. The maximum year/year growth of citations can be observed at the much younger age of 30-45. The data include independent citations only for ERC a and HAS researchers $\mathbf{b}$ and the maximum value of publication output in terms of first/last authored D1 articles $\mathbf{c}$ for HAS researchers, which precedes the maximum citation by only a small number of years

$12 \pm 2.6$ (linguists). These values are based on citations received in independent and peer-reviewed journals. In addition, HSWA filters all dependent and non-peer-reviewed sources (e.g., diploma theses, abstracts, patents). Notably, these restrictions apply for both papers and citations, which explains the very low value for those in language sciences.

The mean age at the highest point of the cumulative year/year citation growth when all researchers were concerned was $41.5 \pm 0.51$ years. Each discipline had different values, with physics researchers as the earliest starters (mean age $34.5 \pm 1.32$ years) and language sciences researchers as the latest (mean age $49.9 \pm 2.10$ years). Regarding the growth itself, the highest growth was observed in physics $(461 \pm 48 \%)$ and the lowest in philosophy $(393 \pm 39 \%)$.

Lastly, we compared male and female scientists across all scientific fields. Both maximal citation growth and highest cumulative citation were reached numerically earlier by 
female scientists, but the differences were not statistically significant (maximal growth $0.64 \pm 1.7$ years earlier, $p=0.13$ and highest citation $0.16 \pm 1.0$ years earlier, $p=0.66$ ) .

The citation characteristics of HAS researchers in each discipline, including the maximal numerical values separately, are summarized in Table 2B and Fig. 2 b.

\section{First/last author papers trend-HSWA}

The highest number of D1 papers was reached at a mean age of $48.4 \pm 0.5$ years. The earliest were in the physical sciences $(46.0 \pm 1.6$ years $)$, and the latest were in literature and the linguistic sciences $(52.2 \pm 5.5$ years $)$.

The maximum growth of D1 publications was produced at an age of $44.6 \pm 0.5$ years, with physics researchers starting first $(40.5 \pm 1.5$ years $)$ and literature and linguistic sciences researchers last $(51.4 \pm 4.7$ years $)$.

Age at the highest number of D1 papers and the growth characteristics are listed in Table 3 and Fig. 2c. The actual values for the total number of citations received and the number of D1 articles over a period of five years are presented for each scientific discipline in Fig. 3.

\section{Gender differences}

We have also analyzed the data after stratifying the cohorts according to the gender of the researchers. The designation was based on the name of the researcher, and the comparison included 284 female and 1849 male researchers. Although women reached both maximal growth (on average 1.27 years earlier) and maximal citation (on average 0.6 years earlier) earlier, than male scientists in the same scientific disciplines, these differences were not statistically significant ( $p=0.13$ and $p=0.65$, respectively).

Table 3 Number of D1 publications in the last five years for HAS researchers

\begin{tabular}{|c|c|c|c|c|c|c|c|c|c|}
\hline & \multirow[b]{3}{*}{$\mathrm{N}$} & \multicolumn{4}{|c|}{ Highest growth of D1 publications } & \multicolumn{4}{|c|}{ Maximal number of D1 publications } \\
\hline & & \multicolumn{2}{|l|}{ Age } & \multicolumn{2}{|c|}{ Growth percentage } & \multicolumn{2}{|l|}{ Age } & \multicolumn{2}{|l|}{ Value } \\
\hline & & Mean & $\mathrm{CI}( \pm)$ & Mean & $\mathrm{CI}( \pm)$ & Mean & $\mathrm{CI}( \pm)$ & Mean & $\mathrm{CI}( \pm)$ \\
\hline Agriculture & 119 & 48.31 & 1.963 & $181 \%$ & $14 \%$ & 49.51 & 2.164 & 2.01 & 0.36 \\
\hline Biology & 272 & 40.48 & 1.218 & $229 \%$ & $8 \%$ & 46.49 & 1.246 & 6.38 & 0.55 \\
\hline Chemistry & 246 & 44.11 & 1.496 & $239 \%$ & $10 \%$ & 50.21 & 1.401 & 7.97 & 0.88 \\
\hline Earth sci. & 80 & 50.12 & 2.515 & $195 \%$ & $18 \%$ & 49.72 & 2.427 & 2.10 & 0.42 \\
\hline Economics & 74 & 47.49 & 2.549 & $165 \%$ & $19 \%$ & 47.29 & 2.7 & 0.84 & 0.21 \\
\hline Engineering & 167 & 49.8 & 1.866 & $194 \%$ & $11 \%$ & 51.99 & 1.976 & 3.55 & 0.60 \\
\hline Language sci. & 22 & 51.36 & 4.699 & $150 \%$ & $31 \%$ & 52.22 & 5.451 & 0.22 & 0.12 \\
\hline Mathematics & 151 & 44.48 & 1.872 & $214 \%$ & $16 \%$ & 47.87 & 1.866 & 4.13 & 0.62 \\
\hline Medicine & 378 & 43.86 & 1.064 & $225 \%$ & $8 \%$ & 47.81 & 1.05 & 5.05 & 0.46 \\
\hline Philosophy & 45 & 48.27 & 3.74 & $196 \%$ & $28 \%$ & 48.57 & 3.791 & 0.75 & 0.27 \\
\hline Physics & 202 & 40.47 & 1.54 & $250 \%$ & $11 \%$ & 46.03 & 1.55 & 6.95 & 0.60 \\
\hline Entire sample & 1756 & 44.55 & 0.469 & $218 \%$ & $4 \%$ & 48.36 & 0.534 & 4.00 & 0.19 \\
\hline
\end{tabular}

CI $95 \%$ confidence interval 
(A)

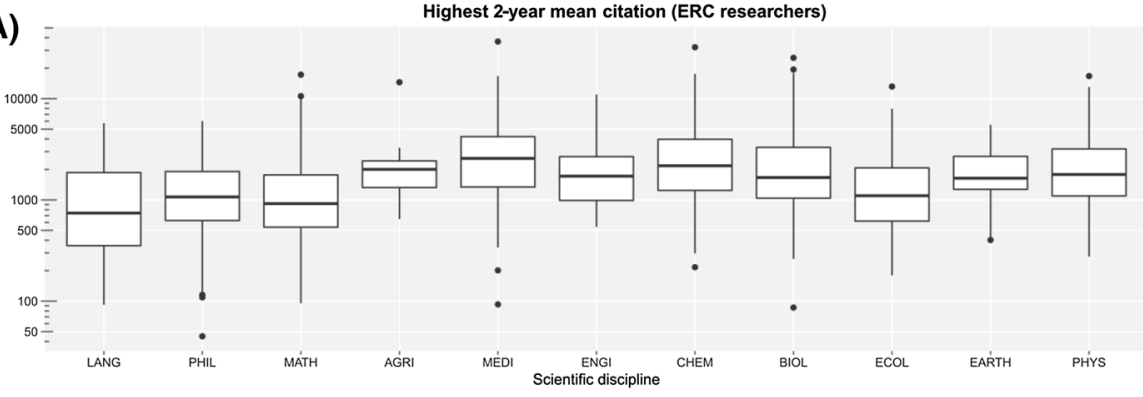

(B)

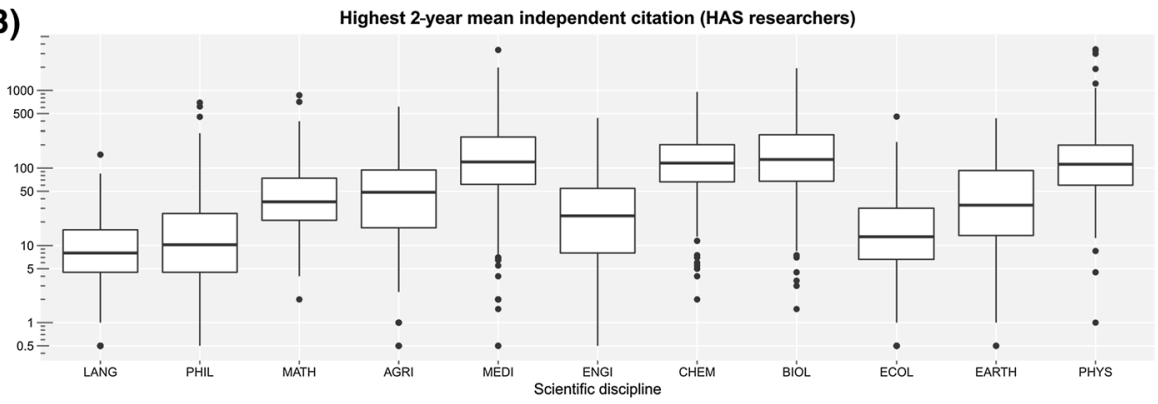

(C)

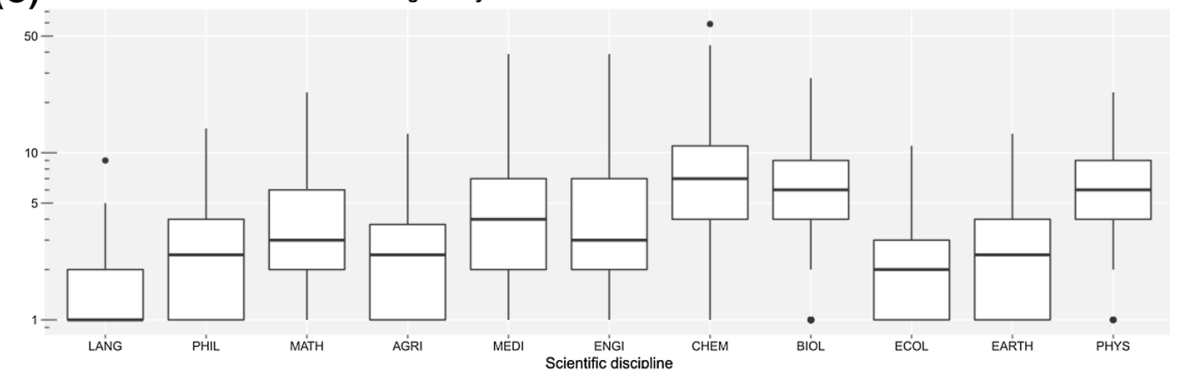

Fig. 3 When comparing scientific disciplines, the absolute values exhibit a magnitude of difference, with highest citation mean for biologists, chemists, and medical sciences. Data are provided for the citations of ERC researchers (a), the citations of HAS researchers (b) and the number of D1 articles for HAS researchers (c)

\section{Momentum fellows output}

Finally, the Hungarian researchers comprised three distinct cohorts with different age distributions. Nearly all Momentum Grant holders belonged to younger cohorts than the Doctors of the Academy, while Members of the Academy comprised the eldest cohort (minimum-median-maximal birth year: Members of the Academy: 1920-1945-1975, Doctors of the Academy: 1923-1952-1981; Momentum fellows: 1968-1975-1985, respectively). After computing the age-specific publication performance, we compared Momentum fellows to all Hungarian researchers. This analysis was performed separately for each discipline and only for the age cohorts below 50 years. On average, the 
Momentum fellows were in the 73-75th percentiles for the number of D1 papers published and in the 85-89th percentile for the number of independent citations received (Fig. 4).

Fig. 4 The Momentum program increases scientific output. The Momentum program provides approximately one million EUR for a period of five years for researchers below 45 years of age. When performing an agespecific comparison of those who receive a Momentum grant (purple) to other Hungarian researchers (green), the Momentum grantees appear in the 73-75th percentiles with respect to the number of published D1 papers (a) and in the 85-89th percentile when the number of independent citations received is considered (b). (Color figure online)
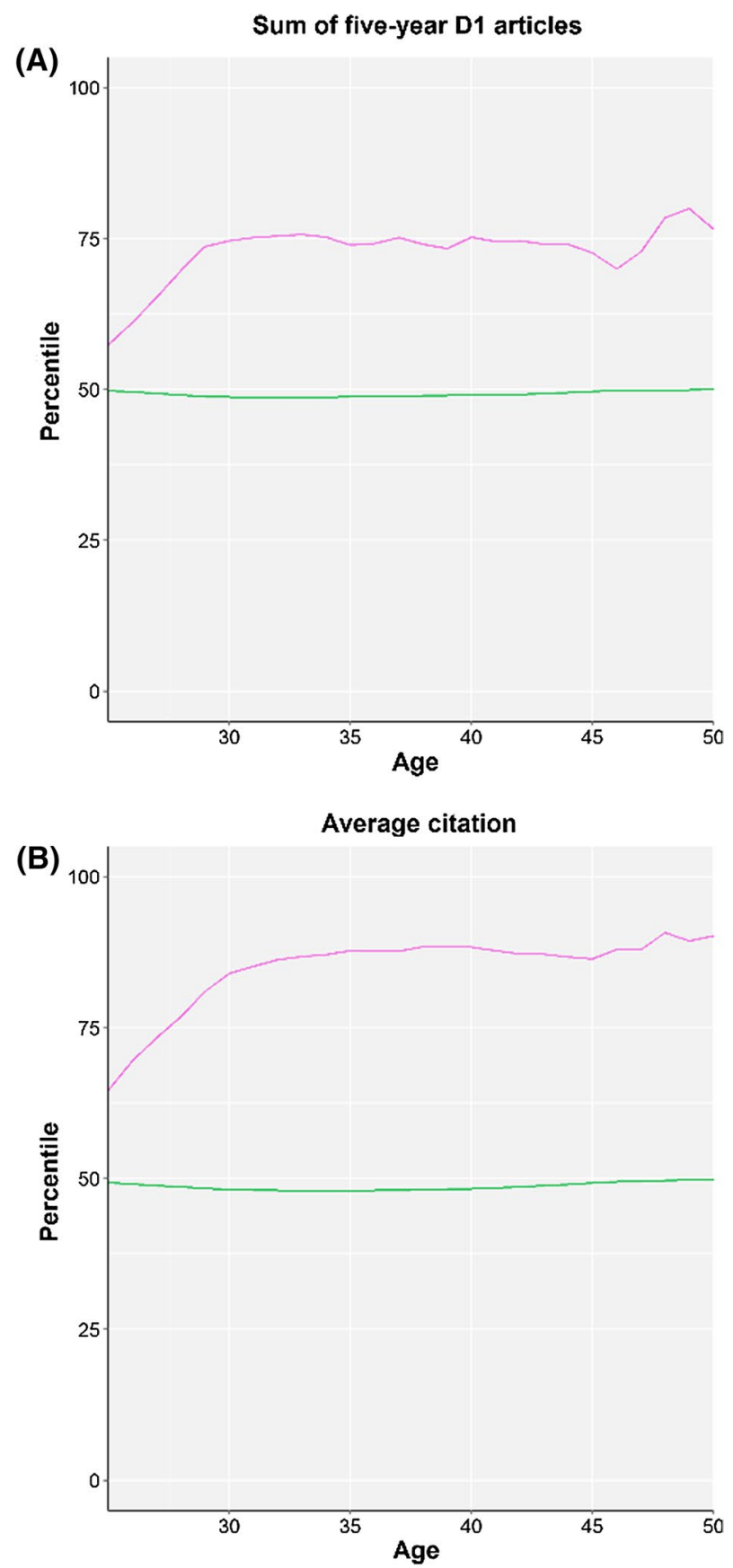


\section{Discussion}

Our first research question addressed whether a Golden Age occurs in a researcher's career. Our general answer is obviously affirmative but with several caveats. The overall increase in life expectancy ensures that the Golden Age exhibits an increasing trend, with the "glass ceiling" currently higher than any time before. However, a "glass ceiling" nevertheless remains. That is, life expectancy remains a constraint, with its strong relationship with the length of active age.

Our literature survey reveals the dynamic character of the Golden Age although this term has yet to appear in the literature. Publications from the 1950s or 1960s locate the most creative time period of scholarly careers in the thirties, whereas most recent publications (including ours) tend to indicate the second half of the forties.

Our data reveal an unexpected degree of predictability of the Golden Age in most analyzed categories. For example, $48.4 \pm 0.53$ years was identified as the age with the highest number of D1 publications, irrespective of field. This finding might be helpful in designing research funding schemes, particularly those that consist of several phases conditional on age and publication record [in Hungary, Momentum is such a scheme (Gyorffy et al. 2018)]. The period of the Golden Age is not the only key question when the time dimension of individual scholarly performance is scrutinized. Our study finds that most research (or academic) careers require decades to reach their peak. However, it is not only the time required to reach this peak that is of interest. The length of the Golden Age itself varies over a wide range, reflecting to a significant extent the real value of the scholarly performance that precedes and/or generates the Golden Age. Complicating the problem further, performance during the years immediately preceding the Golden Age must also be analyzed to determine the extent to which this development had an organic character.

It has to be clarified that length and peak are closely interrelated in our perception of scholarly careers. To be brief: analyzing peaks makes it necessary to understand lengths, because, with a few exceptions, a peak is a peak hinting at Golden Age only if it is supported by a career in research of adequate length.

Both the numbers of publications and citations may be regarded as quantitative and, obviously, as qualitative indicators. The greater the number of a scholar's publications or citations is, the closer we are to identifying that scholar's Golden Age. However, this fundamental indicator has its limits. For example, the citation numbers of certain authors may increase rapidly owing to negative reactions to a questionable research result. Such citations might be termed "deterrent" citations. If scholars receive unwarranted attention, the quality of their publications is not necessarily correlated with their citation numbers (García et al. 2019). The situation is further complicated by a recent case in which an article was revised because it contained incorrect data but whose original version continued to be widely cited after the revision was published (da Silva and Dobránszki 2018). However, addressing the impact of such citations on citation statistics exceeds the scope of this study.

Identifying Golden Ages in diverse research careers may be of substantial help in certain areas of career analysis. For example, using our approach, the optimal timing of offering employment to researchers or providing them with lucrative grants could be established. Contrary trends that indicate a widening gap between apparent publication potential and performance were also observed. Obtaining sizeable grants may negatively affect the publication performance of certain researchers because such grants encourage a mistaken feeling of overconfidence. The contribution of present work to research policy, especially to the allocation of grants consists of its demonstrating the role of field-specific "Golden 
Age" in the output expected from any grant-holder. Matching the applicant's age with "Golden Age" characteristic of the given field of science may have a value in supporting a successful grant decision.

In an alternative approach, the length of the Golden Age itself could be measured by setting annual benchmarks for citations (e.g., 250). Assuming the Golden Age begins when this benchmark is reached, the number of years could be counted when the number of citations remains over this benchmark. This "product cycle" approach could be helpful in evaluating individual scholarly performance when grants are distributed. For example, it may be likely that individual scholarly performance will decline years after the Golden Age ends. Citation data could remain impressive but be steadily lower than in preceding years.

However, caution would be in order for conclusions drawn from the preceding comments. Our argument is based on the assumption that scholarly performance is adequately reflected by scientometric data. However, primarily for researchers belonging to older generations, the focus of their scholarly endeavors may be shifting increasingly towards tuition work, fundraising and research management. Therefore, it could occur that while the results of their research are increasing, they are reflected by the scientometric data of their junior teammates. That is, the scholarly input of the senior colleagues may appear in the citations of their younger disciples. However, measuring this impact is beyond our current research abilities.

We must note several additional limitations to our research. The first concerns data reliability. Google Scholar (GS) served as our main data source. GS represents a very rich, in-depth citation database. However, it does not support sorting non-independent citations. We were thus unable to separately categorize researchers with above-average levels of nonindependent citations. This limitation is a problem since only independent citations indicate the scientific impact of a publication or, more broadly, an author. This apparent shortcoming of GS harms our study's consistency. The reason is that HSWA filters citations for independence, making this database methodologically incompatible with GS to a certain extent.

The second limitation, which we were unable to resolve, is the lack of an internationally accepted nomenclature of the fields of science (as, for example, in economics on the website of the Journal of Economic Literature-www.aeaweb.org/jel). The use of different citation databases implies the acceptance of different scientific nomenclatures. Problems arise with boundaries between fields of science typically unrelated with respect to content, for example, in an article addressing the use of IT in medicine, a paper discussing the property rights aspects of photogrammetry or a study analyzing the mathematics of Big Data. These are examples of the uncertainty of assigning a given publication to one "official" field of science or another. In addition, there are imprecisely defined boundaries between, for example, mathematics and IT sciences, biology and medicine, and labor economics and sociology. The problem of overlapping fields of science may be aggravated by the authors themselves. Their interest in publishing in higher-ranking scholarly journals may encourage them to submit their research to such top journals, which are easier to access owing to their belonging to less competitive fields of science.

The values of measures of individual scholarly performance peak during the Golden Age. However, the length of this period of maximum performance varies across scientific fields, as does the age at which one reaches one's peak. Generally, mathematicians tend to reach their Golden Age earlier and social scientists later. However, even in the latter case, the Golden Age has an upper limit: currently approximately 50 years of age. Our results may help better tailor selection criteria in grants that target different age groups in different disciplines. 
Acknowledgements Open access funding provided by Semmelweis University (SE). The study was supported by the 2018-1.3.1-VKE-2018-00032, 2018-2.1.17-TET-KR-00001, and KH-129581 grants of the National Research, Development and Innovation Office, Hungary. The authors acknowledge the support of ELIXIR Hungary (www.elixir-hungary.org).

Open Access This article is licensed under a Creative Commons Attribution 4.0 International License, which permits use, sharing, adaptation, distribution and reproduction in any medium or format, as long as you give appropriate credit to the original author(s) and the source, provide a link to the Creative Commons licence, and indicate if changes were made. The images or other third party material in this article are included in the article's Creative Commons licence, unless indicated otherwise in a credit line to the material. If material is not included in the article's Creative Commons licence and your intended use is not permitted by statutory regulation or exceeds the permitted use, you will need to obtain permission directly from the copyright holder. To view a copy of this licence, visit http://creativecommons.org/licenses/by/4.0/.

\section{References}

Abramo, G., D’Angelo, C. A., \& Di Costa, F. (2018). The effects of gender, age and academic rank on research diversification. Scientometrics, 144(2), 373-387.

Akbaritabar, A., Casnici, N., \& Squazzoni, F. (2018). The conundrum of research productivity: A study on sociologists in Italy. Scientometrics, 114(3), 859-882.

Bayer, A. E., \& Dutton, K. W. (1977). Career age and research professional activities of academic scientists. Test of alternative nonlinear models and some implications for higher education faculty policies. Journal of Higher Education, 48(3), 259-282.

Bonaccorsi, A., \& Daraio, C. (2003). Age effects in scientific productivity. The case of the Italian National Research Council (CNR). Scientometrics, 58(1), 49-90.

Cole, S. (1979). Age and scientific performance. American Journal of Sociology, 84(4), 958-977.

Costas, R., van Leeuwen, T. N., \& Bordons, M. (2010). A bibliometric classificatory approach for the study and assessment of research performance at the individual level: The effects of age on productivity and impact. Journal of the American Society for Information Science and Technology, 61(8), 1564-1581.

da Silva, J. A., \& Dobránszki, J. (2018). Citation inflation: the effect of not correcting the scientific literature sufficiently, a case study in the plant sciences. Scientometrics, 116(2), 1213-1222.

Dennis, W. (1966). Creative productivity between the ages of 20 and 80 years. Journal of Gerontology, 21(1), 1-8.

Devlin, K. (1998). The language of mathematics: making the invisible visible. New York and Basingstoke: WH Freeman and Co. Ch. 5.

Fox, M. F. (1983). Publication Productivity among scientist: A critical review. Social Studies of Science, 13(2), 285-305.

García, J. A., Rodriguez-Sánchez, R., \& Fdez-Valdivia, J. (2019). Do the best papers have the highest probability of being cited? Scientometrics, 118(1), 885-890.

Gingras, Y., Larivière, V., Macaluso, B., \& Robitaille, J.-P. (2008). The Effects of aging on researchers' publication and citation patterns. PLOS ONE, 3(12), e4048. https://doi.org/10.1371/journal.pone.00040 48.

Gusenbauer, M. (2019). Google scholar to overshadow them all? comparing the sizes of 12 academic search engines and bibliographic databases. Scientometrics, 118(1), 177-214.

Győrffy, B., Nagy, A. M., Herman, P., \& Török, Á. (2018). Factors influencing the scientific performance of momentum grant holders: An evaluation of the first 117 research groups. Scientometrics, 117(1), 409-426. https://doi.org/10.1007/s11192-018-2852-1.

Hartley, J. (2019). Some reflections on being cited 10,000 times. Scientometrics, 118(1), 375-381.

Kahneman, D. (2011). Thinking, fast and slow (p. 499). New York: Farrar, Straus and Giroux.

Kawaguchi, D., Kondo, A., \& Saito, K. (2016). Researchers' career transitions over the life cycle. Scientometrics, 109(3), 1435-1454.

Knorr, K. D., Mittermeir, R., Aichholzer, G., \& Waller, G. (1979). Individual publication productivity as a social position effect in academic and industrial research units. In F. Andrews (Ed.), The effectiveness of research groups in six countries (pp. 55-94). Cambridge: Cambridge University Press.

Lee, S., \& Bozeman, B. (2005). The impact of research collaboration on scientific productivity. Social Studies of Science, 35(5), 673-702.

Lehman, H. C. (1953). Age and achievement (p. 359). Princeton: Princeton University Press.

Lehman, H. C. (1958). The Chemist's most creative years. Science, 127(3308), 1213-1222. 
Lehman, H. C. (1960). The age decrement in outstanding scientific creativity. American Psychologist, 15(2), $128-134$.

Lima, H., Silva, T. H. P., Moro, M. M., Santos, R. L. T., Meira, W., Jr., \& Laender, A. H. F. (2015). Assessing the profile of top Brazilian computer science researchers. Scientometrics, 103(3), 879-896.

Liu, L., Wang, Y., Sinatra, R., Giles, C. L., Song, C., \& Wang, D. (2018). Hot streaks in artistic, cultural, and scientific careers. Nature, 559, 396-399.

Martín-Martín, A., Orduna-Malea, E., \& López-Cózar, E. D. (2018). Coverage of highly-cited documents in Google Scholar, Web of Science, and Scopus: A multidisciplinary comparison. Scientometrics, 116(3), 2175-2188.

Pelz, D. C., \& Andrews, F. M. (1966). Scientists in organizations. Productive climate for research and development. New York: Wiley.

Rørstad, K., \& Aksnes, D. W. (2015). Publication rate expressed by age, gender and academic position-a large-scale analysis of Norwegian academic staff. Journal of Infometrics, 9(2), 317-333.

Sinatra, R., Wang, D., Deville, P., Song, C., \& Barabási, A. L. (2016). Quantifying the evolution of individual scientific impact. Science, 354(6312), aaf5239.

Sugimoto, C. R., Sugimoto, T. J., Tsou, A., Milojević, S., \& Larivière, V. (2016). Age stratification and cohort effects in scholarly communication: a study of social sciences. Scientometrics, 109(2), 997-1016.

Verleysen, F. T., \& Ossenblok, T. L. B. (2017). Profiles of monograph authors in the social sciences and humanities: an analysis of productivity, career stage, co-authorship, disciplinary affiliation and gender, based on a regional bibliographic database. Scientometrics, 111(3), 1673-1686.

Wallner, B., Fieder, M., \& Iber, K. (2003). Age profile, personnel costs and scientific productivity at the University of Vienna. Scientometrics, 58(1), 143-153.

Way, S. F., Morgan, A. C., Clauset, A., \& Larremore, D. B. (2017). The misleading narrative of the canonical faculty productivity trajectory. PNA., 114(44), E9216-E9223.

Zuckerman, H., \& Merton, R. K. (1972). Age, aging and age structure in science. A theory of age stratification. In M. W. Riley, M. Johnson, \& A. Foner (Eds.), Aging and society (Vol. 3). New York: Russel Sage Foundation.

\section{Affiliations}

\section{Balázs Győrffy ${ }^{1,2}$ (D) Gyöngyi Csuka ${ }^{3}$ Péter Herman ${ }^{1,2}$ - Ádám Török ${ }^{4,5}$}

1 Department of Bioinformatics, Semmelweis University, Túzoltó utca 7-9., Budapest 1094, Hungary

2 TTK Cancer Biomarker Research Group, Institute of Enzymology, Magyar Tudósok körútja 2, Budapest 1117, Hungary

3 Department of Economics, University of Pannonia, Egyetem u. 10, Veszprém, Hungary

4 Department of International Economics, University of Pannonia, Egyetem u. 10, Veszprém, Hungary

5 Department of Economics, Budapest University of Technology and Economics, Magyar Tudósok körútja 4, Budapest 1117, Hungary 